\title{
Controlling Tyrophagus putrescentiae Adults in LED-Equipped Y-Maze Chamber
}

\author{
Sang-Min Lee $\cdot$ Jeong-Bin Lee $\cdot$ Hoi-Seon Lee*
}

\section{LED-Equipped Y-Maze Chamber에 대한 긴털가루응애 성충의 방제효과}

\author{
이상민 • 이정빈 • 이회선*
}

Received: 22 December 2014 / Accepted: 7 January 2015 / Published Online: 30 June 2015

(C) The Korean Society for Applied Biological Chemistry 2015

\begin{abstract}
To evaluate four different light-emitting diodes (LEDs) as potential attractants for Tyrophagus putrescentiae adults, attractiveness of blue $(470 \mathrm{~nm})$, green $(520 \mathrm{~nm})$, yellow $(590 \mathrm{~nm})$, and red $(625 \mathrm{~nm})$ LEDs were investigated at 20, 40, and $60 \mathrm{~lx}$ luminance intensity in LED-equipped Y-maze chamber and compared with the response to black light bulb (BLB), which is used in commercial traps. The BLB, the blue LED, the green LED, the yellow LED, and the red LED did not show the attractive to $T$. putrescentiae adults. These results suggested that four LEDs tested could not be used for environment-friendly control of $T$. putrescentiae adults.
\end{abstract}

Keywords attractants $\cdot$ environment-friendly control $\cdot$ lightemitting diode trap $\cdot$ Tyrophagus putrescentiae

S.-M. Lee

Jeonju Hanil High School, Jeonju 560-818, Republic of Korea

J.-B. Lee

Jeonju Kijun Woman High School, Jeonju 560-869, Republic of Korea

H.-S. Lee

Department of Bioenvironmental Chemistry, College of Agriculture \& Life Science, Chonbuk National University, Jeonju 561-756, Republic of Korea

*Corresponding author (H.-S. Lee: hoiseon@jbnu.ac.kr)

This is an Open Access article distributed under the terms of the Creative Commons Attribution Non-Commercial License (http://creativecommons. org/licenses/by-nc/3.0/) which permits unrestricted non-commercial use, distribution, and reproduction in any medium, provided the original work is properly cited.
긴털가루응애(Tyrophagus putrescentiae)는 절지 동물문 중 거미 강 진드기목에 속하는 것으로 대부분은 자유생활을 하고 있으 나 일부는 기생생활을 하면서 따뜻하거나 습기가 많은 상태에 서 바이러스와 박테리아 등의 병원성균을 매개한다(Franzolin 등, 1999). 긴털가루응애는 형태적으로나 생활사에서 곤충과는 상당 히 다른 면을 갖고 있으며, 수많은 저장곡물이나 고지방과 단 백질을 함유하는 달걀, 햄, 치즈 및 견과 등의 저장식품을 오염 시키는 종이다(Aygun 등, 2007; Jeon 등, 2012b). 이와 같이 저곡해충에 오염되면 영양분 함량이나 식물종자 발아율을 감소 시켜서 막대한 경제적 손실을 초래하며(Krantz, 1955), 오염된 저장농산물 및 저장식품을 다루는 식품산업관련 종사자나 농민 들에게 알레르기 관련 질환이나 급성장염(Jeon 등, 2012b; Yang 등, 2014) 및 전신과민증을 일으킨다(Matsumoto 등, 1996). 이 렇게 심각한 피해를 주는 긴털가루응애를 방제하기 위한 유기 인계 합성살비제의 일종인 벤질벤조에이트, 디브틸팔레이트 및 디에칠토루아마이드의 연용과 오남용 등으로 인한 환경오염 및 대상 해충의 저항성 발달이 전세계적으로 보고되고 있다 (Tabashnik, 1994; Yang 등, 2002). 이러한 화학적 방제법의 단 점을 보완하기 위해서 최근 긴털가루응애를 비롯한 저곡해충을 방제하기 위한 방법으로 접착트랩, 음파 및 광원을 이용한 친 환경 물리적 저곡해충 방제제 개발에 많은 연구가 꾸준히 진행 되고 있다(Chu 등, 2003; Park 등, 2011; Kim 등, 2012; Yang 등, 2013). 그 중에서도 기존 광원에 비해 높은 에너지 효 율과 선택적인 파장조절이 가능한 발광다이오드(light emitting diode: LED)를 이용한 친환경 저곡해충방제를 위한 연구가 주 목되고 있다(Yeh과 Chung, 2009; Oh과 Lee, 2010; Kim과 Lee, 2012). 따라서 본 연구팀은 LED를 이용한 긴털가루응애의 행동반응을 제작된 저곡용 $\mathrm{LED}$ 트랩장치를 이용하여 실험을 $470 \mathrm{~nm}$ (청색), $520 \mathrm{~nm}$ (녹색), $590 \mathrm{~nm}$ (황색) 및 $625 \mathrm{~nm}$ (적 색) 광원에서 실시하였다. 
본 연구에 사용한 긴털가루응애는 전북대학교 농업생명과학 대학 생물환경화학과 응용식물생화학실험실 곤충사육실에서 살 비제에 도태하지 않은 감수성 개통으로 10 년 이상 사육 한 것 을 사용하였다. 긴털가루응애 사육에 필요한 먹이로는 치어사료 (고려 특수 사료 1호)와 에비오제 ${ }^{\circledR}$ (삼일식품, Korea)를 $1: 1$ (w/w) 의 비율로 섞은 혼합 사료를 $105^{\circ} \mathrm{C}$ 에서 1 시간 동안 멸균 시킨 것을 건조하여 사용하였다. 혼합 사료에 사용된 치어사료의 조 성은 조단백(44.0\%), 조회분 $(17.0 \%)$, 조섬유 $(4.0 \%)$, 조지방 $(3.0 \%)$, 인 $(2.0 \%)$ 및 칼슘 $(1.8 \%)$ 등의 성분으로 구성되어 있다. 긴털가루응애 사육은 플라스틱상자 $(20.5 \times 20.5 \times 20.5 \mathrm{~cm})$ 에 상대 습도 유지 및 긴털가루응애의 도망을 방지하지 위해 포화염화 나트륨 수용액을 약 $0.5 \mathrm{~cm}$ 의 높이로 채우고, 사육 상자보다 작 은 플라스틱 상자 $(12.5 \times 12.5 \times 7.0 \mathrm{~cm})$ 에 준비한 혼합사료와 함께 진드기를 넣은 후 뚜껑을 덮어서 온도 $27 \pm 1^{\circ} \mathrm{C}$ 와 상대습도 $70 \pm 5 \%$ 을 유지하면서 빛이 차단된 암조건에서 사육하였다.

파장은 씨엘라이트(Ciel Light Corp., Korea)에서 구입하여 사 용하였으며, 저곡해충의 LED 광원에 대한 주광성 행동반응을 검정하기 위해 가시광선 영역의 청색 $\mathrm{LED}(470 \pm 10 \mathrm{~nm}, 15.0 \pm 3.1$ lumenous flux (lm), CL-1W-UBB), 녹색 LED $(520 \pm 5 \mathrm{~nm}$, $45.0 \pm 3.5 \mathrm{~lm}, \mathrm{CL}-1 \mathrm{~W}-\mathrm{UPGB})$, 황색 LED $(590 \pm 5 \mathrm{~nm}, 40.0 \pm 10.0$ $\mathrm{lm}, \mathrm{PP} 592-8 \mathrm{~L} 61-\mathrm{AOBI})$ 와 적색 $\mathrm{LED}(625 \pm 10 \mathrm{~nm}, 35.0 \pm 1.2$ $\mathrm{lm}, \mathrm{CL}-1 \mathrm{~W}-\mathrm{URB}$ )를 본 연구를 위한 광원으로 선발하였다. 양 성대조구로는 해충 포집기에서 주로 사용되는 BLB (315$400 \mathrm{~nm}$, F8T5 BLB: Sankyo-Denki Co. Ltd., Japan)를 대조구 로 하여 생리활성을 비교하였다.

LED 장치 및 생물검정. 긴털가루응애에 대한 주광성 행동반응 판별장치(LED-Equipped Y-Maze Chamber)는 LED광원에 대한 저곡해충 쌀바구미의 행동반응실험에서 사용된 연구장치를 참 고하였다(Figs. 1A와 B) (Jeon 등, 2012a). 긴털가루응애의 경 우 동체 길이가 0.2-0.4 mm로 매우 작으며 날개를 갖지 못하 여 이동성이 떨어지고 크기가 작은 저곡해충의 주광성 행동반 응을 관찰하기 위하여 본 연구수행에 알맞은 긴털가루응애 맞 춤형 장치를 제작하였고, 이를 저곡해충 주광성 행동반응 판별 장치에 삽입하여 실험에 사용하였다(Fig. 1C). Fig. 1과 같이 제 작된 주광성 행동반응 판별장치는 중앙에 위치한 곤충투입구를 기준으로 양쪽에 가림막을 설치하였으며, 가림막을 기준으로 한 쪽에는 광원을 배치하여 광조건을 형성하였으며, 다른 한쪽에는 암조건을 유지시켜 주었다. 주광성 행동반응의 탐색은 중앙의 곤충투입구를 통해 투입된 저곡해충이 특정파장의 빛에 따라 나 타내는 행동반응을 판별하는 식으로 진행되었다. 긴털가루응애 의 $\mathrm{LED}$ 에 대한 주광성 행동반응은 4 가지 파장에서 제작된 저 곡해충 주광성 행동반응 판별장치에서 진행되었다. 실험에 사용 된 긴털가루응애는 암수가 같은 비율로 혼합된 50 마리를 주광 성 행동반응 판별장치의 해충투입구에 방사시켜 진행하였다. 각 파장별 광량을 20, 40 및 $60 \mathrm{~lx}$ 로 달리하여 실험을 진행하였으 며, 빛에 노출된 저곡해충이 광원방향으로 이동한 개체를 양성 주광성 행동반응으로 광조건(light choice), 암조건으로 이동하거 나 광에 대한 반응을 보이지 않으면 음성주광성 행동반응으로 암조건(dark choice), 아무런 행동반응을 보이지 않은 개체는 선 택 없음(no choice)로 분류하였다. LED의 광량은 광원으로부터 $700 \mathrm{~mm}$ 위치된 조도계(LM-322; AS ONE Co., Ltd., Japan)을 사용하여 측정되었다.

통계. $\mathrm{LED}$ 주광성 행동반응 판별장치에서 얻어진 유인활성 결 과는 3반복으로 진행되었으며 SPSS (ver. 12, SPSS INC.,

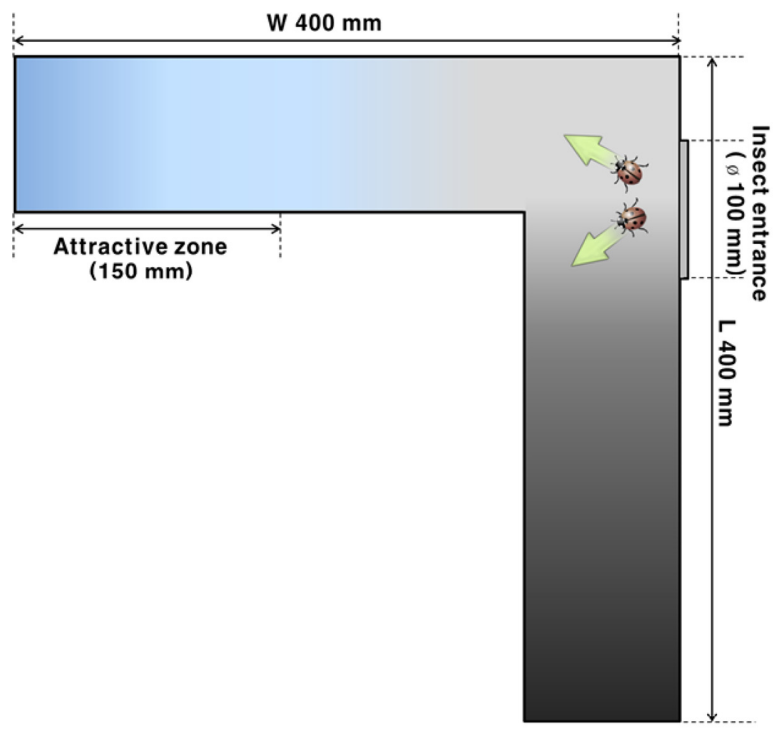

(A)

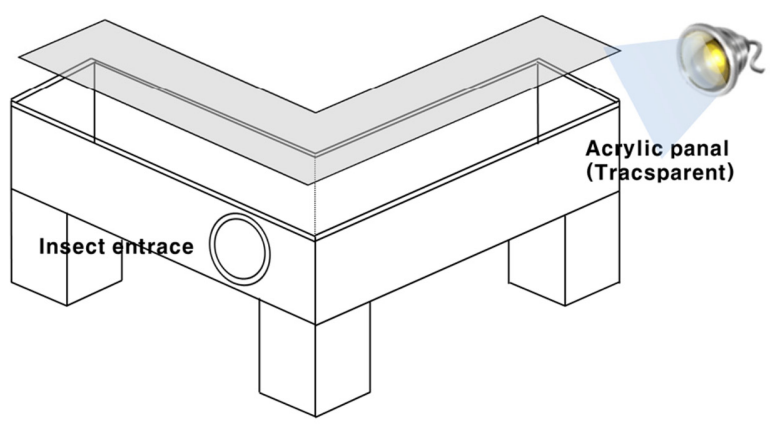

(B)

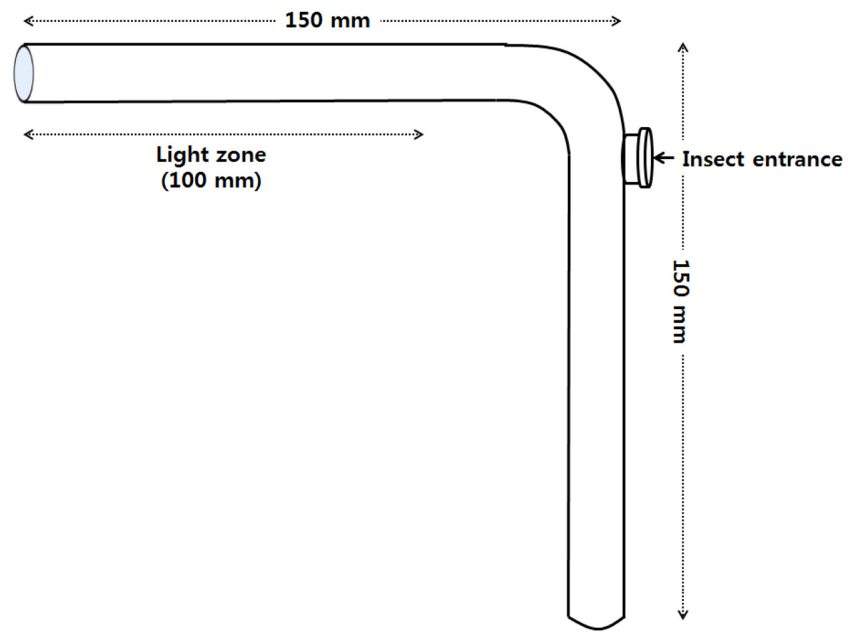

(C)

Fig. 1 Model of cross section (A), three dimension (B) and insert tube (C) in modified Y-maze.

USA)를 이용하여 평균표준오차 또는 백분율 $(\%)$ 로 결과값을 나타내었다. 또한 분산분석(ANOVA)을 이용하여 결과 값의 유 의성을 검정하였으며, 사후검정으로는 Tukey's HSD test를 사 용하였다. 
Table 1 Attraction rate of $T$. putrescentiae adults to light emitting diodes at various luminance intensities (lx) and various light exposure times $(\min )^{\mathrm{a})}$

\begin{tabular}{|c|c|c|c|c|}
\hline \multirow{2}{*}{ Wavelengths } & \multirow{2}{*}{$\begin{array}{l}\text { Luminance } \\
\text { intensity (lx) }\end{array}$} & \multicolumn{3}{|c|}{ Attraction rate $($ Mean \pm SEM) } \\
\hline & & Light choice & No choice & Dark choice \\
\hline \multirow{3}{*}{$\begin{array}{c}470 \pm 10 \mathrm{~nm} \\
\text { (Blue) }\end{array}$} & 20 & $2.8 \pm 2.3$ & $40.9 \pm 3.2$ & $6.3 \pm 2.2$ \\
\hline & 40 & $3.5 \pm 2.6$ & $39.8 \pm 2.8$ & $6.7 \pm 2.2$ \\
\hline & 60 & $3.2 \pm 2.5$ & $41.6 \pm 2.1$ & $5.2 \pm 3.1$ \\
\hline \multirow{3}{*}{$\begin{array}{c}520 \pm 5 \mathrm{~nm} \\
\text { (Green) }\end{array}$} & 20 & $2.8 \pm 2.0$ & $38.3 \pm 3.4$ & $8.9 \pm 2.7$ \\
\hline & 40 & $4.2 \pm 2.8$ & $40.9 \pm 2.0$ & $4.9 \pm 2.2$ \\
\hline & 60 & $3.9 \pm 2.2$ & $41.3 \pm 2.3$ & $4.8 \pm 1.3$ \\
\hline \multirow{3}{*}{$\begin{array}{c}590 \pm 5 \mathrm{~nm} \\
\text { (Yellow) }\end{array}$} & 20 & $5.3 \pm 3.1$ & $39.6 \pm 1.9$ & $5.1 \pm 2.1$ \\
\hline & 40 & $2.9 \pm 2.0$ & $42.3 \pm 2.8$ & $4.8 \pm 2.3$ \\
\hline & 60 & $2.7 \pm 1.8$ & $46.2 \pm 2.4$ & $1.1 \pm 0.7$ \\
\hline \multirow{3}{*}{$\begin{array}{l}625 \pm 10 \mathrm{~nm} \\
\quad(\text { Red })\end{array}$} & 20 & $1.2 \pm 0.9$ & $46.2 \pm 2.3$ & $2.6 \pm 2.0$ \\
\hline & 40 & $5.4 \pm 2.7$ & $41.7 \pm 1.7$ & $2.9 \pm 1.6$ \\
\hline & 60 & $2.3 \pm 1.7$ & $45.7 \pm 1.2$ & $2.0 \pm 0.8$ \\
\hline $\mathrm{BLB}^{\mathrm{b})}$ & - & $2.2 \pm 1.3$ & $44.5 \pm 1.7$ & $3.3 \pm 2.0$ \\
\hline
\end{tabular}

${ }^{a)}$ Each value is the average of three determinations at each intensity after $120 \mathrm{~min}$ exposure, using 50 insects per replication.

${ }^{b)} \mathrm{A}$ black light bulb (BLB) served as the positive control.

긴털가루응애의 각각 파장별 광량을 20,40 및 $601 x$ 로 달리 하여 진행한 실험에서 청색 $(470 \pm 10 \mathrm{~nm}) \mathrm{LED}$ 는 $20 \mathrm{~lx}$ 에서 평균 2.8 개체가 유인, 평균 6.3 개체가 기피 반응을 보였으며 아무런 행동반응을 보이지 않는 개체수가 40.9마리로 확인되었으며, 40 $1 \mathrm{x}$ 에서는 3.5 마리 유인, 6.7 마리 기피, 39.8 마리 무반응을 보였 고, $601 \mathrm{x}$ 에서 3.2 마리 유인, 5.2 마리 기피, 그리고 41.6 마리가 무반응을 보였다(Table 1). 녹색 $(520 \pm 5 \mathrm{~nm}) \mathrm{LED}$ 는 $20 \mathrm{~lx}$ 에서 2.8 마리 유인, 8.9 마리 기피, 38.3마리가 무반응, $401 \mathrm{x}$ 에서는 4.2 마리 유인, 4.9마리 기피, 40.9마리 무반응과 $601 x$ 에서 3.9마리 유인, 4.8마리 기피, 41.3마리가 무반응을 보였다. 황색 $(590 \pm 5 \mathrm{~nm}) \mathrm{LED}$ 는 $201 \mathrm{x}$ 에서 5.3마리 유인, 5.1마리 기피, 39.6 마리가 무반응, $40 \mathrm{~lx}$ 에서는 2.9 마리 유인, 4.8 마리 기피, 42.3 마리 무반응과 $601 \mathrm{x}$ 에서 2.7마리 유인, 1.1 마리 기피, 46.2마리 가 무반응을 보였다. 또한 적색 $(625 \pm 10 \mathrm{~nm}) \mathrm{LED}$ 는 $20 \mathrm{~lx}$ 에서 1.2 마리 유인, 2.6마리 기피, 46.2 마리가 무반응, $401 \mathrm{~lx}$ 에서는 5.4 마리 유인, 2.9마리 기피, 41.7마리 무반응과 $601 x$ 에서 2.3마리 유인, 2.0마리 기피, 45.7마리가 무반응을 보였다. 긴털가루응애 는 사용된 청색, 녹색, 황색 및 적색 $\mathrm{LED}$ 파장과 20,40 및 $60 \mathrm{~lx}$ 광량에서 특별한 행동반응특성을 발견하지 못하였다. 더 불어 양성대조구로 이용된 $\mathrm{BLB}$ 에서도 긴털가루응애는 음성 및 양성주광성 반응을 보이지 않았다.

Antignus (2000)의 연구문헌에 따르면 곤충의 주광성 행동반 응은 광을 수용하는 감각기관 감각기관에서 광을 인지하여 양 성 또는 음성주광성 행동반응을 나타내며, 감각기관 세포에 따 라 인지할 수 있는 파장 및 광량이 다르게 나타난다고 보고하 였다. 하지만 광에 대한 주광성 행동반응 실험결과에서는 긴털 가루응애는 광에 대해 유의성 있는 행동반응을 나타내지 않았 다. 이에 본 연구결과는 긴털가루응애의 광을 수용할 수 있는 감각기관이 퇴화되었거나 긴털가루응애의 행동반응은 광이 아 닌 후각 및 촉각에 의해 발생하는 것으로 유추하였고, 광원을 이용한 기계적 방제가 불가능 한 것으로 판단하였다. 하지만 광
원의 조사시간에 따른 행동반응 유추실험에서 한 시간 이상 광 원에 노출되었을 때에 죽은 긴털가루응애 개체가 다수 발견되 었으며, 3 시간 이상 광원에 노출되었을 때 모든 긴털가루응애 가 죽은 것을 볼 수 있었다. 이는 긴털가루응애가 약 $90 \%$ 수 분으로 이루어졌고, 표피가 다른 곤충 종에 비해 현저히 얇은 막으로 구성되어 있기 때문에 광 조사에 따른 탈수에 의한 것 으로 예측되며, 이러한 결과는 향후 광원에 따른 긴털가루응애 의 살비연구에 유용하게 사용될 수 있을 것으로 판단된다.

\section{초 록}

긴털가루응애 성충을 청색 $(470 \mathrm{~nm})$, 녹색 $(520 \mathrm{~nm})$, 황색 $(590$ $\mathrm{nm})$ 과 적색 $(625 \mathrm{~nm})$ light-emitting diode (LED)에서 파장별 광 량을 20, 40 및 $601 x$ 로 달리하여 주광성 행동반응 판별장치 (LED-equipped Y-maze chamber)에서 상업적 양성대조구 BLB 와 유인활성을 비교하였다. 긴털가루응애는 사용된 청색, 녹색, 황색 및 적색 $\mathrm{LED}$ 파장과 20,40 및 $60 \mathrm{~lx}$ 광량에서 특별한 행동반응특성을 발견하지 못하였으며, 양성대조구로 이용된 BLB 에서도 긴털가루응애는 음성/양성주광성 반응을 보이지 않았다. 이러한 결과를 근거로 긴털가루응애는 $\mathrm{LED}$ 주광성 행동반응 판별장치에서는 친환경적 해충방제 가능성을 제시하지 못했다.

Keywords 긴털가루응애 · 유인활성 · 친환경적 해충방제 · $\mathrm{LED}$ 주광성 행동반응 판별장치

감사의 글 본 논문은 농촌진흥청 연구사업(세부과제명: 농식품 저장시설지 내 LED 광원을 이용한 저곡해충용 방제기술 개발, 세부과제번호: PJ01004501) 의 지원에 의해 이루어진 것임.

\section{References}

Antignus Y (2000) Manipulation of wavelength-dependent behavior of insects: An IPM tool to impede insects and restrict epidemics of insectborne viruses. Virus Res 71, 213-20.

Aygun O, Yaman M, and Durmaz H (2007) A survey on occurrence of Tyrophagus putrescentiae (Acari: Acaridae) in Surk, a traditional Turkish dairy product. J. Food Eng 78, 878-81.

Chu CC, Jackson CG, Alexander PJ, Karut K, and Henneberry TJ (2003) Plastic cup traps equipped with light-emitting diodes for monitoring adult Bemisia tabaci (Homoptera: Aleyrodidae). J Econ Entomol 96, 543-6.

Franzolin MR, Gambale W, Cuero RG, and Correa B (1999) Interaction between toxigenic Aspergillus flavus Link and mites (Tyrophagus putrescentiae (Schrank)) on maize grains: effects on fungal growth and aflatoxin production. J Stored Prod Res 35, 215-24.

Jeon JH, Oh MS, Cho KS, and Lee HS (2012a) Phototactic response of the rice weevil, Sitophilus oryzae Linnaeus (Coleoptera: Curculionidae), to light-emitting diodes. J Korean Soc Appl Biol Chem 55, 35-9.

Jeon JH, Yang JY, and Lee HS (2012b) Acaricidal activities of materials derived from Pyrus ussuriensis fruits against stored food mites. $J$ Food Prot 75, 1258-62.

Kim MG and Lee HS (2012) Attraction effects of LED trap to Spodoptera exigua adults in the greenhouse. J Appl Biol Chem 55, 273-5.

Krantz GW (1955) Some mites injurious to farm-stored grain. $J$ Econ Entomol 48, 754-5.

Matsumoto T, Hisano T, Hamaguchi M, and Miike T (1996) Systemic anaphylaxis after eating storage-mite-contaminated food. Intl Arch Allergy Imm 109, 197-200. 
Oh MS and Lee HS (2010) Development of phototactic test apparatus equipped with light source for monitoring pests. J Appl Biol Chem 53, 248-52.

Park JA, Seok J, Parasad SV, and Kim Y (2011) Sound stress alters physiological processes in digestion and immunity and enhances insecticide susceptibility of Spodoptera exigua. Korea J Appl Entomol 50, 39-46.

Tabashnik BE (1994) Evolution of resistance to Bacillus thuringiensis. Ann Rev Entomol 39, 47-79.

Yang JY, Cho KS, Chung NH, Kim CH, Suh JW, and Lee HS (2013) Constituents of volatile compounds derived from Melaleuca alternifolia leaf oil and acaricidal toxicities against house dust mites. J. Korean Soc.
Appl. Biol. Chem. 56, 91-4.

Yang JY, Kim MG, Park JH, Hong ST, and Lee HS (2014) Evaluation of benzaldehyde derivatives from Morinda officinalis as anti-mite agents with dual function as acaricide and mite indicator. Sci Rep 4. doi: 10.1038/srep07149.

Yang YC, Lee SG, Lee HK, Kim MK, Lee SH, and Lee HS (2002) A piperidine amide extracted from Piper longum L. fruit show activity against Aedes aegypti mosquito larvae. J Agric Food Chem 50, 3765-7.

Yeh N and Chung JP (2009) High-brightness LEDs-energy efficient lighting sources and their potential in indoor plant cultivation. Renew Sust Energ Rev 13, 2175-80. 